\title{
Hydrocephalus - what's new?
}

"Not a lot" may be the general impression, but then it is easy to forget that, until the advent of shunts (almost 50 years ago), hydrocephalus was usually fatal. It is probably true to say that further fundamental advances have been slow in coming, but this has not been through lack of endeavour. What has occurred over the years is an understanding of how shunts malfunction (and technical attempts to combat this, including the development of endoscopic treatment for certain types of hydrocephalus) and a greater awareness of the metabolic and hydrodynamic changes that occur in the brain as a result of hydrocephalus (fig 1). Although perhaps overdue, reasonable studies on long term follow up of patients with hydrocephalus are now becoming available.

The prevalence of congenital and infantile hydrocephalus is between 0.48 and 0.81 per 1000 births (live and still), ${ }^{12}$ and a significant percentage of these patients will be left with persistent neurological deficits. ${ }^{23}$ In the United Kingdom and Ireland, the number of shunt operations is estimated to be 3500-4000 a year by the Cambridge based UK Shunt Registry. In the United States, about 125000 shunt procedures are carried out annually at an estimated cost of $\$ 100$ million. ${ }^{4}$ In relatively recent times in the United Kingdom, the number of paediatric neurosurgeons has increased, and in many regions the care of children with hydrocephalus has been inherited from the general paediatric surgeons.

\section{Cerebrospinal fluid (CSF) circulation}

The generally accepted view is that the CSF circulation is one of bulk flow, from the choroid plexus (production) to the pacchionian granulations (absorption). The evidence for this came in the 1960s when Welch and Friedman ${ }^{5}$ found that the pacchionian granulations could act as valves, and Di Chiro ${ }^{6}$ found that 24 hours after radionucleotide cisternography, the greatest concentration of isotope

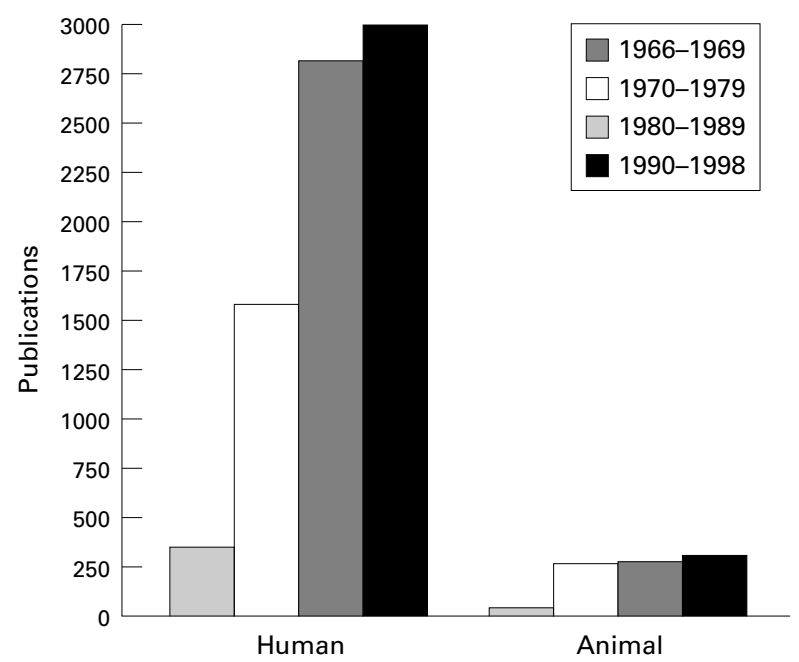

Figure 1 Number of publications on hydrocephalus between 1966 and 1998. Taken, with permission, from $\mathcal{F}$ P McAllister, Neurol Res 2000;22:3. was seen around the sagittal sinus. However, it is difficult to square this theory with the following facts: the pacchionian granulations only develop at the time of closure of the fontanels; $80-90 \%$ of radioactive isotope injected into the lumbar CSF is absorbed in the spinal canal; and computed tomography-cisternography has shown penetration of contrast media into brain and spinal cord parenchyma itself. ${ }^{7}$

An alternative view, proposed by Greitz et $a l,{ }^{7}$ is that the main absorption of CSF occurs through the blood capillaries and not the pacchionian granulations. This view is based on results obtained from cardiac gated, flow sensitive magnetic resonance imaging (MRI) and radioisotope cisternography. In communicating hydrocephalus, CSF flow across the foramen magnum is significantly reduced as a result of a restriction of arterial pulsation during systole. Greitz et al propose that any process that restricts the arterial pulsation (either decreased compliance of the vessel itself or of the subarachnoid space) will result in communicating hydrocephalus (termed by them restricted arterial pulsation hydrocephalus or RAP-hydrocephalus). In obstructive hydrocephalus, Greitz et al argue that the ventricular dilatation causes compression of the cortical veins, resulting in an increase in cerebral blood volume and intracranial hypertension (venous congestion hydrocephalus or VC-hydrocephalus).

Although our understanding of CSF dynamics is still incomplete (and the theories of Greitz et al may well be disproved), it seems likely that dynamic MRI will help to clarify this subject. Although CSF dynamics may seem of purely academic interest, from a clinical perspective, the distinction between communicating and obstructive hydrocephalus remains important as it effects treatment options.

\section{Cerebral metabolic changes in hydrocephalus}

In studying hydrocephalus, the cause (and any direct cerebral effects this disease process may have) must be distinguished from the effect of raised intracranial pressure (ICP) and brain deformation as a result of the ventriculomegaly. Most studies, in both animal and humans, initially concentrated on cerebral blood flow and found that hydrocephalus was usually associated with a decrease in cerebral blood flow (40-64\%) but not to levels that might cause ischaemic damage. ${ }^{89}$

It has long been believed that "hydrocephalus is mainly a white matter disease", ${ }^{10}$ and axonal degeneration has been commonly observed. ${ }^{9}$ Likewise, periventricular reactive gliosis has been well documented. ${ }^{9}$ Certainly there is no correlation between cognitive outcome and thickness of cerebral mantle (until the latter is less than $2 \mathrm{~cm}$ ). ${ }^{911}$ However, cytoarchitectural studies have shown that, in untreated hydrocephalus, the neurones become hyperchromatic and pyknotic. ${ }^{9}$ Electron miscroscopic studies have shown that the dendrites are affected early in hydrocephalus and that there is a relatively short window of opportunity for this to be reversed by shunting. ${ }^{9}$

Studies of the consequences of hydrocephalus on cerebral metabolism have used autoradiographic techniques, positron emission tomography, and NMR spectroscopy. ${ }^{12}$ Using in vitro NMR spectroscopy, Jones et $a l^{13}$ 


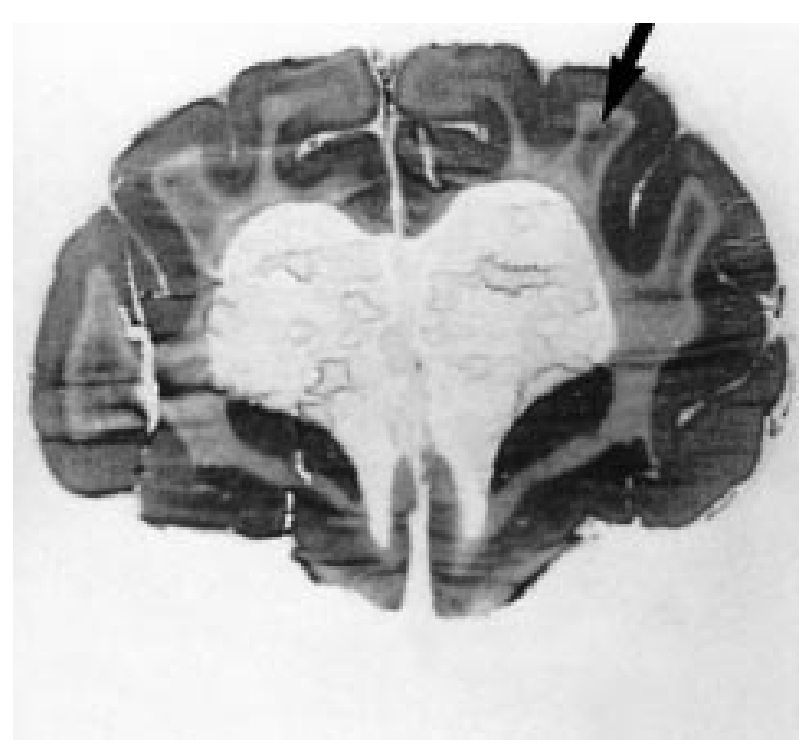

Figure 2 Autoradiographs of local cerebral glucose utilisation showing a region of significantly raised activity located in the middle of the gyri (arrow). Taken, with permission, from Chumas et al. ${ }^{16}$

showed early changes in cell membrane compounds, followed later by a decrease in energy metabolites and finally changes in amino acid/neurotransmitter levels in untreated hydrocephalic rats. The degree of reversibility of these cellular changes depends on the duration of the hydrocephalus. ${ }^{14}$

Studies analysing cerebral glucose utilisation have generally shown reduced metabolism in cortical structures. ${ }^{15}$ However, in a neonatal kitten model, increased activity was seen in the white matter in keeping with anaerobic glycolysis. This pattern of increased activity matched areas of decreased myelination, suggesting that the added metabolic burden of myelination made the white matter particularly susceptible to ischaemic damage (fig 2). ${ }^{16}$ Again, these changes were not completely reversed by shunting.

\section{Treatment options}

NON-SURGICAL

Diuretics (frusemide and acetazolamide) and steroids are known to decrease CSF production. Diuretics are still often used in neonatal patients with post-haemorrhagic hydrocephalus $(\mathrm{PHH})$ despite reports of side effects such as acidosis, $\mathrm{CO}_{2}$ retention, electrolyte disturbance, etc. A recent multicentre randomised controlled trial actually showed a higher rate of shunt placement and increased neurological morbidity in the group receiving diuretics. ${ }^{17} 18$

Likewise intraventricular fibrinolytic treatment has been used in an attempt to prevent permanent obstruction of the CSF pathways in $\mathrm{PHH}$, but studies to date have not shown a decrease in the number of patients requiring a shunt. ${ }^{18}$ Fortunately the incidence of $\mathrm{PHH}$ is decreasing with better general care, careful control of blood pressure, temperature, and blood gases, better ventilation, and the appropriate use of antenatal steroids and postnatal surfactant, ${ }^{19}$ but it remains a significant challenge. In passing, it should be noted that the CSF protein concentration ${ }^{20}$ per se is of no consequence with regard to timing of surgical intervention but the degree of cellular debris may be.

Just as the use of diuretics would appear to be futile, the use of regular lumbar punctures should probably be abandoned as it is ineffective ${ }^{1721}$ and carries a risk of introducing infection $\left(9 \%\right.$ in a recent large $\left.\operatorname{trial}^{22}\right)$. Repeated ventricular taps risk not only infection but also the development of "puncture porencephaly" ${ }^{21}$ and again are inadvisable.
SURGICAL

Surgical drainage of CSF appears to date from the time of Hippocrates, but it was not until the 18th century that ventricular drainage (combined with head wrapping and the instillation of toxic agents) was seriously attempted. ${ }^{23}$ By the 19th century, it had become clear that prevention of infection would require internal CSF drainage.

Virtually every cavity has been tried, including the subdural space, the subarachnoid space, the subcutaneous tissues of the scalp, the paranasal sinuses, the thoracic duct, the pleura, the peritoneum, the gall bladder, the ureters, and the bloodstream. The atrium was initially the preferred site for placement of the distal catheter, but atrial shunts have a unique set of complications including endocarditis and glomerulonephritis. They also migrate from the atrium with linear growth of the child, needing surgical revision of the distal catheter. The peritoneum is now the "favoured" site for the distal catheter unless there are problems with absorption or abdominal sepsis. Lumbar peritoneal shunts are rarely used for the treatment of hydrocephalus in children and have been associated with the development of scoliosis and cerebellar tonsillar herniation. ${ }^{24-26}$ This emphasises the deformational potential consequent on altering the hydrodynamic forces of the central nervous system. Intriguingly, this may also explain the hindbrain herniation seen in open spina bifida-where, in effect, the fetus has a lumbar shunt in utero. ${ }^{26}$

Various materials have been used as conduits, including gold, silver, glass, and rubber tubes, and threads of linen and catgut-all of which were suboptimal. ${ }^{23}$ The modern era of shunting began in the 1950 s with the realisation that a one way valve was required and that silicone tubing was the best material for use in manufacture..$^{23}$

\section{Shunts}

Although the subsequent results for treating hydrocephalus were far superior, it soon became apparent that shunts had their limitations. In particular, it became clear that there are three ways in which shunts can malfunction: $(a)$ they can become infected; $(b)$ they can fail mechanically; $(c)$ they can overdrain or underdrain (termed a "functional" failure)..$^{23}$

(a) Shunt infection. Although single institutional studies have reported infection rates of less than $1 \%,{ }^{27}$ most studies have reported rates of the order of $5-10 \%{ }^{28}{ }^{29}$ (and significantly higher than this for neonatal shunts ${ }^{30}$ ). The role of antibiotic prophylaxis has been studied by metaanalysis, ${ }^{23} 29$ and antibiotic cover is recommended. Most shunt infections occur in the first six months after the operation and the most common organisms are staphylococci (Staphylococcus epidermidis, 40\%; Staphylococcus aureus, 20\%). Other species seen include coryneforms, streptococci, enterococci, aerobic Gram-negative rods, and yeasts. ${ }^{23}$ Most shunt infections result from contamination with the patient's own skin flora, which underlines the need for meticulous attention to surgical technique. Unfortunately, once a shunt is infected, it is almost always necessary to remove it and insert a temporary external ventricular drain. Antibiotic treatment alone is sometimes effective in the treatment of infection by Streptococcus and Haemophilus. Apart from the practical problems associated with the treatment of shunt infection, it has been shown that there is an increase in the development of loculated CSF compartments, impaired intellectual outcome, and death after shunt infection. ${ }^{23}$

(b) Mechanical failure. The use of Kaplan-Meier curves to display shunt survival has led to a far greater understanding of shunt failure. Virtually all the studies to date have shown an exponential curve, with about $40 \%$ of shunts failing (including infection) in the first year and 


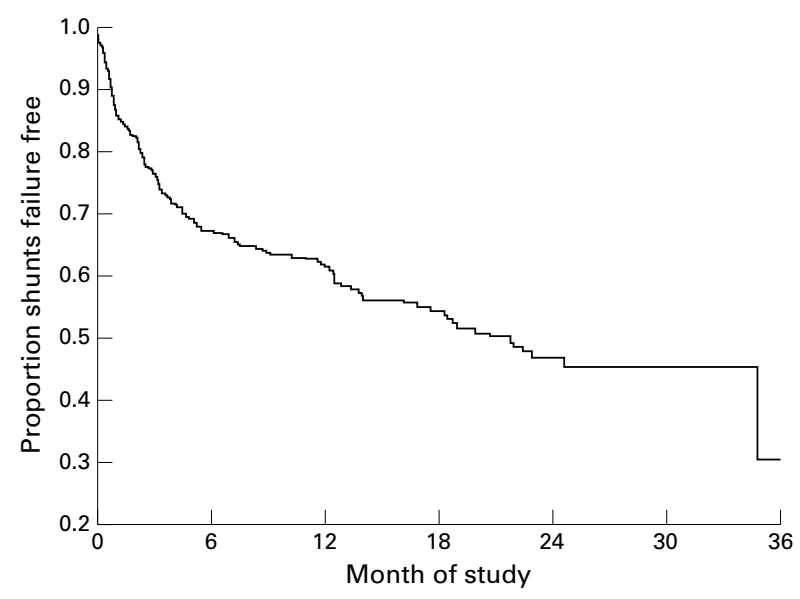

Figure 3 Kaplan-Meier curve for proportion of shunts that are failure free. Taken, with permission, from Drake et al. ${ }^{28}$

then about 5\% a year 23283132 (fig 3). Over 50\% of first shunt failures are due to obstruction, with the vast majority of these occurring at the ventricular catheter. ${ }^{23}$ This is almost certainly a consequence of the fact that all shunts overdrain, so that the ventricular catheter comes to lie against the ependyma and choroid plexus of the ventricle, and these tissues can then become incorporated into and block the holes at the end of the catheter. Although it is reassuring to see collapsed ventricles on a scan, this is probably not ideal for long term shunt functioning. Very occasionally, patients develop slit ventricle syndrome, which is transient symptoms of raised ICP in the setting of a scan that shows small or non-existent ventricles. Although poorly understood, it would appear that these children lose their CSF buffering reserve and are susceptible to episodes of raised pressure in situations that would normally be of no consequence. ${ }^{23}$ This can be a difficult management problem, sometimes requiring formal monitoring of ICP to make the diagnosis. Although there are various treatment options (altering the shunt valve, adding an antisiphon device, skull expansion-for example, subtemporal decompression), this remains one of the most testing conditions to treat in paediatric neurosurgery.

Other shunt malfunctions include fracturing of the tubing (the cause of about $15 \%$ of primary shunt malfunctions), migration of part or all of the shunt (7.5\%) (fig 4 ), and problems with overdrainage $(7 \%) .^{23}$

(c) Functional failure. The cause of functional failure is usually overdrainage. The underlying problem is one of siphoning from the ventricle to the level of the distal tube (over a metre in an adult). This overdrainage can result in subdural haematoma, low pressure symptoms (postural headache and nausea), and craniosynostosis. ${ }^{23}$ Studies have shown that, in normal subjects, the ICP initially decreases continuously from the horizontal to the vertical position and then stabilises (after about $30^{\circ}$ elevation) at -5 to +5 $\mathrm{cm} \mathrm{H}_{2} \mathrm{O}^{24}$ In contrast, in asymptomatic patients with shunts, there is a rapid, near linear fall in ICP with consistently negative upright pressures $\left(-15\right.$ to $\left.-35 \mathrm{~cm} \mathrm{H}_{2} \mathrm{O}\right) .^{31}{ }^{32}$ What is perhaps more surprising therefore is that all patients with shunts do not suffer symptoms of overdrainage. In patients with persistent symptoms, it is possible to alter the valve (see below) or include an antisiphon device in series with the valve. Again, formal monitoring of ICP may be of use in confirming the diagnosis.

In an attempt to overcome the problem of siphoning, several attempts have been made to modify the performance of shunt valves. At present there is a myriad of shunt types which can be broadly classified as follows.

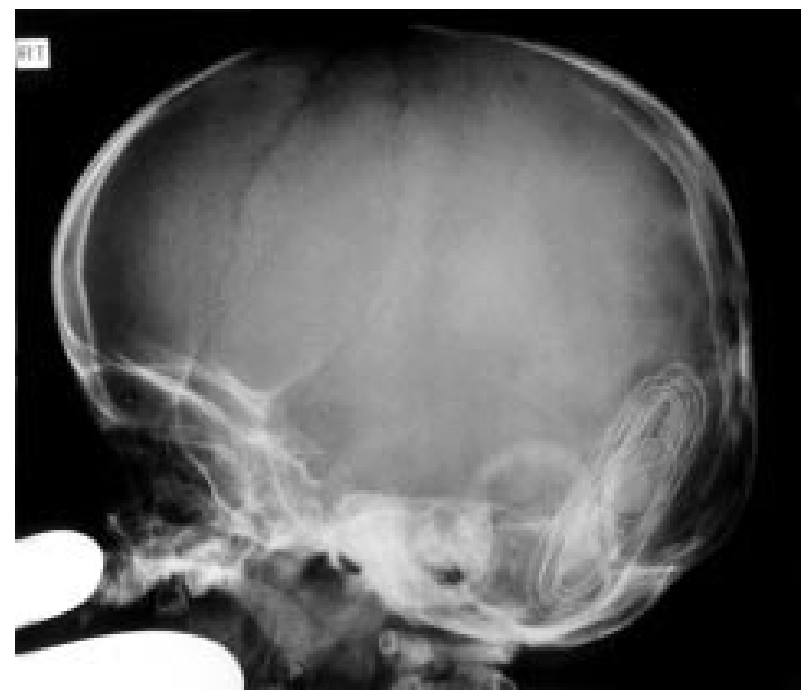

Figure 4 Skull radiograph showing complete migration of a ventriculoperitoneal shunt into the subgaleal space in the occipital region. Taken, with permission, from C Dominguez et al, Childs Nerv Syst 2000;16:493-5.

(1) Differential-pressure valves (ball-in-spring, diaphragm, mitre or slit valves). The valves open at a pressure differential across the valve that is determined by the valve characteristics and is designated low, medium, or high (typically 5, 10 , and $15 \mathrm{~cm} \mathrm{H}_{2} \mathrm{O}$ respectively). Some valves are programmable to allow the pressure setting to be altered after implantation.

(2) Differential-pressure valves with an integral or inline antisiphon device.

(3) Valves that regulate by flow rather than by pressure differentiation.

The cost of a complete shunt system ranges from $£ 350$ to $£ 1100$, and there are about a dozen shunt types on sale in the United Kingdom. Perhaps as a reflection of the intense marketing in this field, there has only been one randomised trial comparing shunt valves. ${ }^{28}$ This found no significant difference between the three types of shunt listed above. This is despite the quite different profile each shunt type has on bench testing ${ }^{28}$ and on testing in vivo. ${ }^{24}$

Using sophisticated statistical techniques, Tuli et al ${ }^{25}$ investigated the risk factors for repeated shunt failures. They found that the failure time from the first procedure was an important predictor of all future failures (with a hazard ratio of 1.5 times for subsequent shunt failures if the original shunt failed within six months of insertion as compared with those that failed after six months). Likewise, patients of less than 40 weeks gestation and between 40 weeks and 1 year of age had a hazard ratio of 2.49 and 1.77 respectively in comparison with patients older than 1 at the time of initial shunt insertion. In this study, certain causes of hydrocephalus (intraventricular haemorrhage, postmeningitis, and tumour) were significant factors in recurrent shunt failure. Concurrent surgical procedure was also noted to increase shunt failure. The fact that these unchangeable patient characteristics correlated with shunt failure (rather than the more easily remedied factors such as shunt design, experience of surgeon, or site of shunt insertion) raises new avenues for research.

\section{Third ventriculostomy}

Open third ventriculostomy (TV) - literally making a hole to connect the third ventricle with the subarachnoid space-was first reported in the 1920s by Dandy, but it had significant mortality. ${ }^{23} 3334$ Subsequently, percutaneous TV techniques were used, but they also had relatively high 


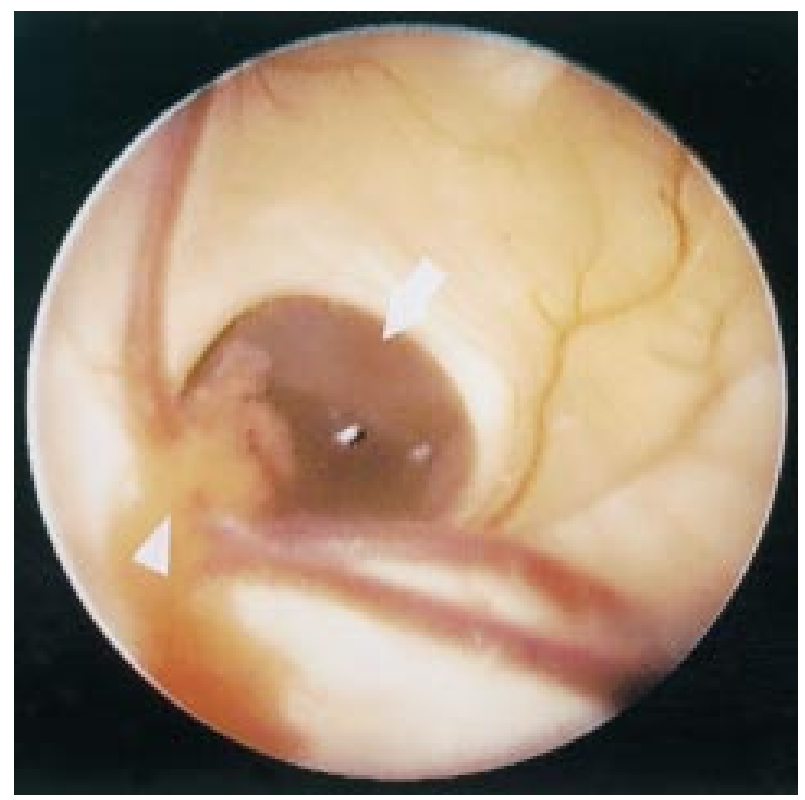

Figure 5 Endoscopic view of the Foramen of Monro. The arrow is on the fornix and pointing to the Foramen of Monro. The arrowhead points to the choroid plexus in the lateral ventricle entering the foramen.

mortality and morbidity. ${ }^{33} 34$ Although Mixter performed the first endoscopic procedure in 1923, it was not until the last two decades that endoscopic TV has grown in popularity as an alternative to shunt placement for patients with triventricular (obstructive) hydrocephalus, ${ }^{23} 3334$ and this procedure is now generally available in most centres in the United Kingdom. This popularity has partly been a response to the problems associated with shunts and partly due to the improvement in optical technology. An additional factor is that endoscopic procedures are aesthetically pleasing (to surgeon and patient alike).

Endoscopic TV entails entering the lateral ventricle, passage through the Foramen of Monro (fig 5), identification of the mamillary bodies, and then perforation of the floor of the third ventricle just anterior to the bifurcation of the basilar artery ${ }^{35}$ (fig 6).

However aesthetically appealing it is, there is no point in performing a TV if the absorptive capacity is abnormal. Unfortunately, there is no easy and reliable method of determining absorptive capacity. Perhaps this lack of certainty goes some way to explaining the results of a recent postal survey which showed a wide range (0-100\%, median $13 \%$ ) of use of TV as the initial treatment for hydrocephalus in various clinical scenarios. ${ }^{36}$

A number of recent studies have described "success" rates of $49-100 \%$ with endoscopic $\mathrm{TV}^{33}{ }^{35}$; however, most of these studies have been descriptive and the outcome measures vague. ${ }^{34}$ Nonetheless, there appears to be some conformity in these studies, with most showing about $70 \%$ of patients with aqueduct stenosis requiring no further surgical intervention. The few studies that have used survival analysis seem to show a different profile from shunted patients, with the curves plateauing fairly early on and with only a few late failures, although these can occur. However, Tuli et $a l{ }^{34}$ when comparing a small group of TV patients (32) with shunted patients (210), found similar survival curves. Certainly in those patients in whom a TV becomes blocked after having been successful for sometime, it is worth repeating the procedure. ${ }^{33}$ Controversy, however, remains over the success rate in children under 6 months of age. ${ }^{33}$

Imaging after TV can be difficult to interpret with marginal changes in ventricular size and the presence of flow

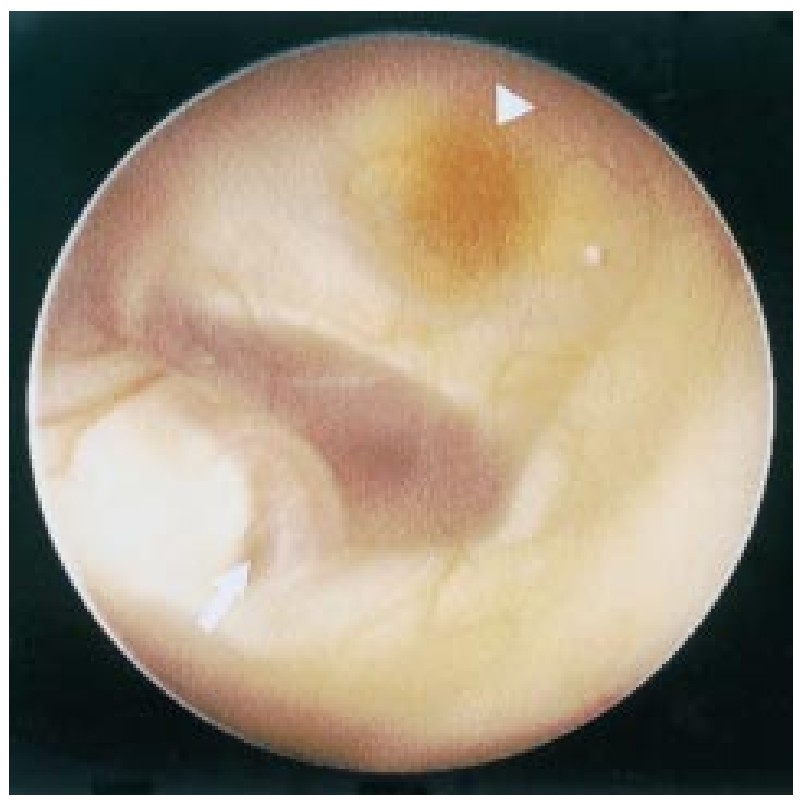

Figure 6 Endoscopic view of the floor of the third ventricle. The structures seen are the basilar artery bifurcation (arrow) immediately anterior to the mamillary bodies. The third ventriculostomy stoma is made anterior to the basilar artery. The arrowhead points to the infundibulum at the base of the pituitary stalk.

voids on MRI scans not being specific enough to be used in isolation to assess functioning of the $\mathrm{TV}^{37}$

Gradually, the complication rate associated with endoscopic TV is becoming manifest. Failure to complete the procedure for technical reasons has been reported in up to $26 \%$ of patients, ${ }^{38}$ and, not surprisingly (fig 6 ), the main complication is haemorrhage secondary to vascular damage. ${ }^{34}$ Other reported complications include cardiac arrest, diabetes insipidus, inappropriate antidiuretic hormone, subdural haematoma, meningitis, and cerebral infarction. ${ }^{34} 3839$ The rate of shunt infection after failed TV is as yet unknown but needs to be quantified. As the potential operative risks with TV are greater than with shunting, careful patient selection is of paramount importance. Although a randomised trial comparing shunt placement with endoscopic $\mathrm{TV}^{34}$ would hopefully answer many of the outstanding questions, there are probably sufficient data available to offer selected patients endoscopic TV.

\section{Outcome}

The natural history for untreated hydrocephalus is poor, with $50 \%$ of children dying before 3 years of age ${ }^{40}$ and only $20-23 \%$ of patients reaching adult life. Of these survivors, only $38 \%$ were of normal intelligence. ${ }^{41}$ Considering the frequency with which shunts are inserted, it is somewhat depressing that better outcome data are still unavailable. Although actual surgical mortality is low, the 10 year death rate for non-tumoral hydrocephalus is of the order of $5-15 \%,{ }^{30}$ and a significant number of these deaths are avoidable and attributable to delay in diagnosis and treatment of shunt malfunction. ${ }^{30}$ Most patients will have neurological deficits $(60 \%$ with motor and $25 \%$ with visual or auditory). ${ }^{3}$

Routine obstetric sonography has shown that the diameter of the atrium of the fetal lateral ventricle is of some prognostic value. If the atrium measures $11-15 \mathrm{~mm}$, the child has a $21 \%$ chance of developmental delay, ${ }^{43}$ whereas, if this measurement is greater than $15 \mathrm{~mm}$, the risk of developmental delay is over $50 \%{ }^{44}$ It is, however, important to compare the ventricular measurement with the head circumference in order to differentiate between 


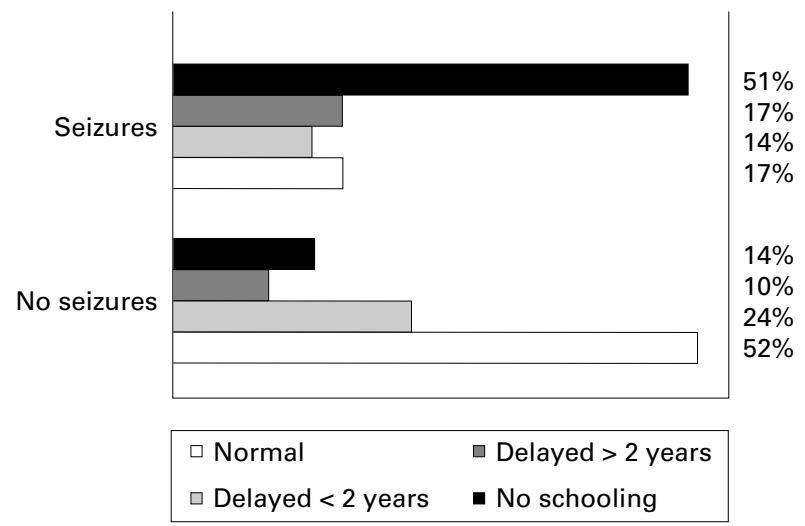

Figure 7 Schooling outcomes in hydrocephalic patients with and without epilepsy. Taken, with permission, from Bourgeois et al. ${ }^{46}$

fetal hydrocephalus and cerebral atrophy. Likewise, the finding of multiple central nervous system and/or extracranial abnormalities is of considerable prognostic value. ${ }^{45}$

\section{EPILEPSY}

For most series of non-tumoral hydrocephalic patients, an overall rate of epilepsy of about $30 \%$ (about $5 \%$ transient seizures and $25 \%$ recurrent) has been reported. ${ }^{46}$ Most of these patients (89\%) have poorly controlled epilepsy and the onset of the epilepsy occurs at roughly the same time as the diagnosis of the hydrocephalus. ${ }^{46}$ Most authors have found a correlation between the cause of the hydrocephalus and the incidence of epilepsy. ${ }^{46}$ Bourgeois et $a l^{46}$ reporting on over 800 patients, found spina bifida to carry a low risk ( $7 \%)$, cerebral malformations and intraventricular haemorrhage to carry a moderate risk (about 30\%), and infection a high risk $(50 \%)$. It is difficult to isolate the epileptogenic effect of catheter placement itself, but certainly electroencephalographic changes related to the catheter have been regularly recorded. ${ }^{46}$

Although it is generally accepted that shunt infection predisposes to epilepsy, controversy continues over the contribution of simple shunt malfunction alone. ${ }^{46}$ Likewise, debate continues over whether seizure activity can indicate shunt malfunction. Bourgeois et $a l^{46}$ found that, in patients with a previous history of epilepsy, a change in seizure pattern was a presenting symptom of shunt malfunction in $28 \%$, whereas seizures as a presenting symptom only occurred in $3 \%$ of children without such a history. It is important therefore that changes in seizure pattern are not ignored. Perhaps more important is the need to distinguish between "hydrocephalic attacks" (decerebrate posturing secondary to raised ICP) and epilepsy.

FUNCTIONAL OUTCOME

Many factors correlate with the final functional and intellectual outcome in children with hydrocephalus, including birth weight, degree of prematurity, presence of structural brain abnormalities, epilepsy, visual and hearing impairment, and other congenital abnormalities. ${ }^{3478}$ Overall, about $50-55 \%{ }^{330} 47$ of shunted hydrocephalic children will achieve an intelligence quotient (IQ) of greater than 80 , with verbal cognitive skills being superior to non-verbal ones. Not surprisingly, epilepsy appears to be an important predictor of poor intellectual outcome in shunted hydrocephalic children, with an IQ $>90$ being seen in $66 \%$ of children without epilepsy compared with $24 \%$ of children with epilepsy. ${ }^{46}$

Reliance on IQ alone, however, has its limitations, and a better guide to functional outcome may be whether the child is able to attend a normal school. ${ }^{49}$ However, this obviously brings into play social/political factors with regard to the appropriate placement for children with special needs. Nonetheless, for children surviving until school age, about $60 \%$ will attend a normal school (half being one to two years behind their age group) and $40 \%$ will require special schooling. ${ }^{30}$ Children who had hydrocephalus secondary to an infection and those who suffered an intraventricular haemorrhage are more likely to need special schooling than those with congenital hydrocephalus. ${ }^{3}{ }^{30}$ Again, epilepsy is a poor prognostic factor, with most hydrocephalic children without epilepsy attending a normal school whereas $50 \%$ of those with seizures are "institutionalised" $" 46$ (fig 7).

Studies of outcome after schooling (presumably the long term aim of treatment) are virtually non-existent. One study has shown that two thirds of children followed through to adulthood were socially independent but living at home with their parents. A further $16 \%$ had left home and were living either on their own or with partners. ${ }^{50}$

\section{What next?}

The treatment of children with hydrocephalus is far from perfect. Hopefully, continued research in the areas outlined in this review will eventually pay dividends. Other areas of research not mentioned but of equal importance include fetal surgery, ${ }^{51}$ mathematical modelling of hydrocephalus (which in the future would be a powerful tool for the understanding and treatment of hydrocephalus as well as other conditions related to brain biomechanics), ${ }^{52}$ and tissue engineering (which aims to create custom designed living implantable devices for diverting CSF. A working tissue engineered shunt is feasible and may one day address some of the problems of interaction between living tissue and an inert polymer). ${ }^{53}$ Certainly, a significant start to improved treatment would be (a) the development of a shunt that was truly physiological and $(b)$ a simple test to determine the natural absorptive capacity of the patient.

At a more basic level, decent data collection is required and more emphasis placed on ascertaining whether new products are of any value rather than allowing marketing to dictate fashion. However, controlled trials are expensive and require large numbers of patients. An alternative may be analysis through the British Shunt Registry, but, to date, variability in reporting rates between centres and differences in diagnostic and treatment strategies has made interpretation difficult.

P CHUMAS

A TYAGI J LIVINGSTON

Departments of Neurosurgery and Paediatric Neurology,

Division of Paediatric Neurosciences,

Leeds General Infirmary, Leeds LS1 3EX, UK

1 Blackburn BL, Fineman RM. Epidemiology of congenital hydrocephalus in Utah, 1940-1979: report of an iatrogenically related "epidemic". Am $\mathcal{F}$ Med Genet 1994;52:123-9.

2 Fernell E, Hagberg G, Hagberg B. Infantile hydrocephalus epidemiology: an indicator of enhanced survival. Arch Dis Child Fetal Neonatal Ed 1994;70:F123-8.

3 Hoppe-Hirsch E, Laroussinie F, Brunet L, et al. Late outcome of the surgical treatment of hydrocephalus. Childs Nervous Syst 1998;14:97-9.

4 Bondurant CP, Jimenez DF. Epidemiology of cerebrospinal fluid shunting. Bondurant CP, Jimenez DF. Epide
Pediatr Neurosurg 1995;23:254-8.

Pediatr Neurosurg 1995;23:254-8.
5 Welch K, Friedman V. The cerebrospinal fluid valves. Brain 1960;83:45469.

6 Di Chiro G. Observation on the circulation of the cerebrospinal fluid. Acta Radiol Diagn (Stockh) 1966;5:988-1002.

7 Greitz D, Greitz T, Hindmarsh T. A new view on the CSF-circulation with the potential for pharmacological treatment of childhood hydrocephalus. Acta Paediatr 1997;86:125-32.

8 da Silva MC, Michowicz S, Drake JM, et al. Reduced local cerebral blood flow in periventricular white matter in experimental neonatal hydrocephaMcAllister JP, Chovan P. Neonatal hydrocephalus. Mechanisms and consequences. Neurosurg Clin North Am 1998;9:73-93.

10 Rubin RC, Hochwald GM, Tiell M, et al. Hydrocephalus. II. Cell number and size, and myelin content of the pre-shunted cerebral cortical mantle. Surg Neurol 1976;5:115-18. 
11 Young HF, Nulsen FB, Weiss $\mathrm{MH}$, et al. The relationship of intelligence and cortical mantle thickness to untreated hydrocephalus. Pediatrics cortical mantl

12 Braun KP, Vandertop WP, Gooskens RH, et al. NMR spectroscopic evaluation of cerebral metabolism in hydrocephalus: a review. Neurol Res 2000;22:51-64

13 Jones HC, Harris NG, Rocca JR, et al. Progressive changes in cortical metabolites at three stages of infantile hydrocephalus studied by in vitro NMR spectroscopy. F Neurotrauma 1997;14:587-602.

14 Jones HC, Harris NG, Rocca JR, et al. Progressive tissue injury in infantile hydrocephalus and prevention/reversal with shunt treatment. Neurol Res 2000;22:89-96.

15 Richards HK, Bucknall RM, Jones HC, et al. The uptake of $\left[{ }^{14} \mathrm{C}\right]$ deoxyglucose into brain of young rats with inherited hydrocephalus. Exp Neurol 1989;103:194-8.

16 Chumas PD, Drake JM, Del Bigio MR, et al. Anaerobic glycolysis preceding white-matter destruction in experimental neonatal hydrocephalus. $\mathcal{F} \mathrm{Neu}-$ rosurg 1994;80:491-501.

17 Tortorolo G, Luciano R, Papacci P, et al. Intraventricular hemorrhage: past, present and future, focusing on classification, pathogenesis and prevenpresent and future, focusing on classific
tion. Childs Nerv Syst 1999;15:652-1.

18 International PHVD Drug Trial Group. International randomised controlled trial of acetazolamide and furosemide in post-haemorrhagic ventricular dilatation in infancy. Lancet 1998;352:433-40.

19 Volpe JJ. Brain injury in the premature infant: is it preventable? Pediatr Res 1990;27:28-33.

20 Brydon HL, Hayward R, Harkness W, et al. Does the CSF protein concentration increase the risk of shunt complications? $B r \quad \mathcal{F}$ Neurosurg 1996;10:267-73.

21 Fulmer BB, Grabb PA, Oakes WJ, et al. Neonatal ventriculosubgaleal shunts. Neurosurgery 2000;47:80-4.

22 Ventriculomegaly Trial Group. Randomised trial of early tapping in neonatal post-haemorrhagic ventricular dilatation. Arch Dis Child 1990;65:3-10.

23 Drake JM, Sainte-Rose C. The shunt book. New York: Blackwell Scientific, 1995.

24 Frim DM, Goumnerova LC. In vivo intracranial pressure dynamics in patients with hydrocephalus treated by shunt placement. $\mathcal{f}$ Neurosurg 2000;92:927-32.

25 Tuli S, Drake JM, Lawless J, et al. Risk factors for repeated cerebrospinal shunt failures in pediatric patients with hydrocephalus. $\mathcal{f}$ Neurosurg 2000;92:31-8.

26 Chumas PD, Kulkarni AV, Drake JM, et al. Lumboperitoneal shunting: a retrospective study in the pediatric population. Neurosurgery 1993;32:376-83.

27 Choux M, Genitori L, Lang D, et al. Shunt implantation: reducing the incidence of shunt infection. $\mathcal{F}$ Neurosurg 1992;77:875-80

28 Drake JM, Kestle JRW, Milner R, et al. Randomized trial of cerebrospinal fluid shunt valve design in pediatric hydrocephalus. Neurosurgery 1998;43:294305.

29 Langley JM, LeBlanc JC, Drake JM, et al. Efficacy of antimicrobial prophylaxis in placement of cerebrospinal fluid shunts: meta-analysis. Clin Infect Dis 1993;17:98-103.

30 Casey AT, Kimmings EJ, Kleinlugtebeld AD, et al. The long-term outlook for hydrocephalus in childhood. Pediatr Neurosurg 1997;27:63-70.
31 Piatt JH Jr, Carlson CV. A search for determinants of cerebrospinal fluid hunt survival: retrospective analysis of a 14-year institutional experience. shunt survival: retrospective analys

32 Sainte-Rose C, Piatt JH, Renier D, et al. Mechanical complications in shunts. Pediatr Neurosurg 1991;17:2-9.

33 Cinalli G, Sainte-Rose C, Chumas PD, et al. Failure of third ventriculostomy in the treatment of aqueductal stenosis in children. $\mathcal{F}$ Neurosurg 1999;90:448-54.

34 Tuli S, Alshail E, Drake JM. Third ventriculostomy versus cerebrospinal fluid shunt as a first procedure in pediatric hydrocephalus. Pediatr Neurosurg 1999;30:11-15.

35 Sainte-Rose C, Chumas PD. Endoscopic third ventriculostomy. Techniques in Neurosurgery 1995;1:176-84.

36 Kestle J,Cochrane D, Alisharan R. The initial treatment of hydrocephalus: an assessment of surgeons' preference between third ventriculostomy and shunt insertion. Neurol Res 2000;22:65-8.

37 Kulkarni AV, Drake JM, Armstrong DC, et al. Imaging correlates of successful endoscopic third ventriculostomy. F Neurosurg 2000;92:915-19.

38 Brockmeyer D, Abtin K, Carey L, et al. Endoscopic third ventirculostomy: an outcome analysis. Pediatr Neurosurg 1998;28:236-40.

39 Buxton N, Punt J. Cerebral infarction after neuroedoscopic third ventriculostomy: case report. Neurosurgery 2000;46:999-1002.

40 Yashon D, Jane JA, Sugar O. The course of severe untreated infantile hydrocephalus. Prognostic significance of cerebral mantle. 7 Neurosurg 1965;23:509-16.

41 Laurence KM, Coates S. The natural history of hydrocephalus. Detailed analysis of 182 unoperated cases. Arch Dis Child 1962;37:345-62.

42 Watkins $\mathrm{L}$, Hayward $\mathrm{R}$, Andar $\mathrm{U}$, et al. The diagnosis of blocked cerebrospinal fluid shunts: a prospective study of referral to a paediatric cerebrospinal fluid shunts: a prospective study of re

43 Patel MD, Filly RA, Hersh D, et al. Isolated mild fetal cerebral ventriculomegaly: clinical course and outcome. Radiology 1994;192:759-64

44 Filly RA, Goldstein RB. Fetal ventricular atrium: 4 th down and $10 \mathrm{~mm}$ to go. Radiology 1994;193:315-17.

45 Bannister CM, Russell SA, Rimmer S, et al. Pre-natal ventriculomegaly and hydrocephalus. Neurol Res 2000;22:37-42.

46 Bourgeois M, Sainte-Rose C, Cinalli G, et al. Epilepsy in children with shunted hydrocephalus. F Neurosurg 1999;90:274-81.

47 Donders J, Canady AI, Rourke BP. Psychometric intelligence after infantile hydrocephalus. Childs Nerv Syst 1990;6:148-54.

48 Dennis M, Fitz CR, Netley CT. The intelligence of hydrocephalic children. Arch Neurol 1981;38:607-15.

49 Hirsch JF. Consensus statement. Long term outcome in hydrocephalus. Childs Nerv Syst 1994;10:64-9.

50 Sgouros S, Malluci C, Walsh AR, et al. Long term complications of hydrocephalus. Pediatr Neurosurg 1995;23:127-32.

51 Clewell WH. Intrauterine shunting procedures. $\mathrm{Br} f$ Hosp Med 1985;34:149-53.

52 Tenti G, Drake JM, Sivaloganathan S. Brain biomechanics: mathematical modeling of hydrocephalus. Neurol Res 2000;22:19-24.

53 Lee I-W, Vacanti JP, Taylor GA, et al. The living shunt: a tissue engineering approach in the treatment of hydrocephalus. Neurol Res 2000;22:105-10.

\section{ADC online submission and review system}

The Editors of $A D C$ are pleased to inform authors and reviewers of its new online submission and review system. Developed by Highwire Press (CA, USA), Bench $>$ Press is a fully integrated electronic system which uses the internet to allow rapid and efficient submission of manuscripts, and for the peer review process to be conducted entirely online. We are the first journal of the BMJ publishing group to go online in this way; the aim, apart from saving trees, is to speed up the frequently frustrating progress from submission to publication.

Authors can submit their manuscript in any standard word processing software. Standard graphic formats acceptable include: .jpg, .tiff, .gif, eps, etc. The text and graphic files are automatically converted to PDF for ease of distribution and reviewing purposes. Authors are asked to approve their submission before it formally enters the reviewing process. On approval, the submission is passed to the editor and/or reviewers via the web. All transactions are secure.

To access the system click on "SUBMIT YOUR MANUSCRIPT HERE" on the ADC homepage: http://www.archdischild.com, or you can access the submission site directly at http://submit-adc.bmjjournals.com.

We are very excited with this new development and would encourage authors and reviewers to use the system where possible. It is simple to use and should greatly improve on the current peer review process. Full instructions can be found on Bench>Press and ADC online. 